\title{
Step-up training for colorectal and gastric ESD and the challenge of ESD training in the proximal colon: results from a German Center
}

\section{(ㄷ)(i) $\Theta$}

\author{
Authors \\ Institution \\ Department of Gastroenterology, Klinikum Augsburg \\ submitted 25.10.2017 \\ accepted after revision 12.2 .2018 \\ Bibliography \\ DOI https://doi.org/10.1055/a-0584-6457 | \\ Endoscopy International Open 2018; 06: E524-E530 \\ (c) Georg Thieme Verlag KG Stuttgart · New York \\ ISSN 2364-3722 \\ Corresponding author \\ Dr. Alanna Ebigbo, Central Clinic of Augsburg - \\ Gastroenterology, Stenglinstr. 2, Augsburg 86156, \\ Germany \\ Fax: +00498214002748 \\ Alanna.ebigbo@gmx.de
}

Alanna Ebigbo, Andreas Probst, Christoph Römmele, Helmut Messmann

\begin{abstract}
Background and study aims The endoscopic submucosal dissection (ESD) of cancerous and precancerous lesions in the gastrointestinal $(\mathrm{Gl})$ tract is an effective but difficultto-learn procedure, especially for Western endoscopists. We developed a step-up training protocol and evaluated its outcome on a single endoscopist using specific performance measures.

Patients and methods The training protocol included a 12 -month period of 50 observational and supervised ESD cases as well as 24 animal procedures. After completion of the protocol, ESD competency was evaluated in the first 30 independent ESD cases. Majority of lesions were located in the stomach and rectum. Performance measures included R0-resection rate, complication rate and resection speed.

Results $\mathrm{R} 0$ resection rate was $93 \%$, complication rate was $7 \%$ and median resection speed was $6,77 \mathrm{~cm}^{2} / \mathrm{h}$. 1 case of delayed perforation with subsequent hemicolectomy occurred in the descending colon.

Conclusion The ESD step-up training protocol used in this study on a single endoscopist showed excellent outcomes for lesions in the rectum and stomach. However, ESD training in the upper colon remains a challenge.
\end{abstract}

\section{Introduction}

Endoscopic submucosal dissection (ESD) for treatment of precancerous and early cancerous lesions in the gastrointestinal tract requires a high level of skill and expertise. The learning curve before a sufficient level of proficiency is attained is steep [1]. Performance measures for definition of proficiency include the curative en bloc resection rate and complication rate as well as speed of resection, usually recorded in $\mathrm{cm}^{2} / \mathrm{h} \mathrm{[2].}$

In Asian countries and especially Japan, ESD remains at a higher level of proficiency compared to Western countries [3]. This difference can be explained not only by the higher prevalence of gastric cancer but also by the standardized training program used for training ESD-endoscopists.

In most ESD centers in Western countries, proficiency has been achieved over several years in a learning-by-doing approach $[1,4]$. However, considering the steep learning curves described in the past, adoption of a step-up approach, similar to that used in Japan may produce better learning outcomes [2,5-7]. This step-up approach involves observation, animal training as well as ESD under expert supervision prior to independent ESD procedures $[2,8]$. The purpose of this study was to demonstrate implementation of a simple step-up training program in a real-life setting. Achievement of competency by a single endoscopist and clinical outcomes of the first 30 ESD procedures are demonstrated here.

\section{Patients and methods}

\section{Trainee}

The trainee (A.E.) is a gastroenterologist with about 7 years of endoscopy experience in a high-volume referral center in Augsburg, Germany. At the onset of training, he was proficient in 

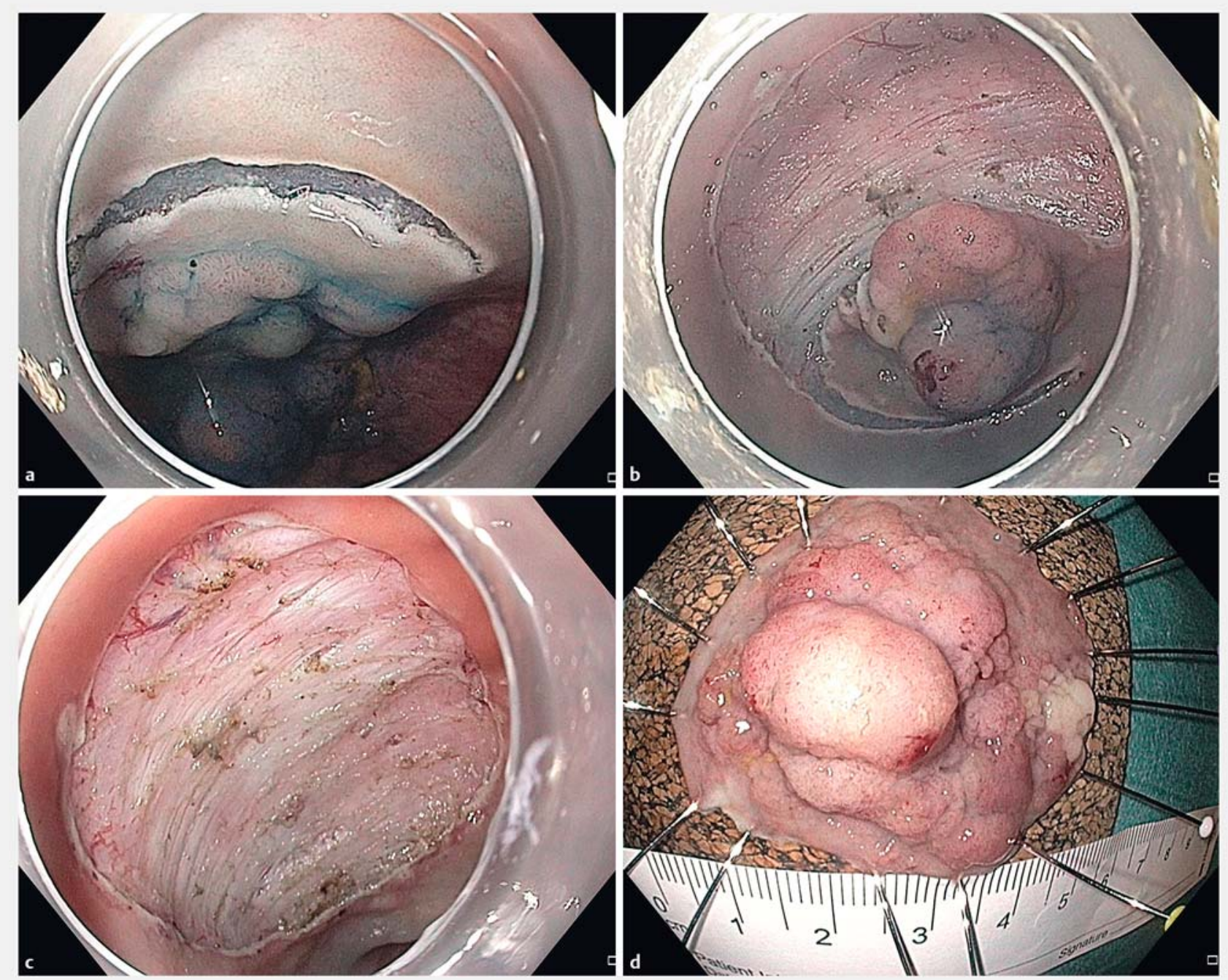

Fig. 1 ESD of a laterally spreading tumor in the rectum. Histology showed tubular adenoma with high-grade intraepithelial neoplasia. R0 resection.

most advanced therapeutic procedures with a case load of about 100 endoscopic mucosal resections (EMR) per year. Apart from observation, the trainee had no personal ESD experience.

\section{Trainers}

Two experts (A.P. and H.M.), with about 12 years of ESD experience and a case load of about 150 ESD cases per year conducted the training program.

\section{Training strategy}

The training strategy involved the following steps:

1. Observation

2. Mentor-apprentice stage

3. Animal training workshop

4. Clinical ESD under expert supervision

5. Observation of Japanese experts

6. Independent ESD
Training and ESD was done using the hook knife and followed the basic steps of mucosal incision and submucosal dissection as shown in $>$ Fig. 1a to $\mathbf{F i g . 1 d}$. Size and position of the lesion, gravity and tissue traction as well as optimal positioning of the patient were taken into consideration before each procedure.

\section{Step 1: Observation}

In the first phase of training, 10 complete ESD procedures were observed and an understanding of basic techniques, strategies, pre-interventional diagnosis, choice and characterization of lesions for ESD, instruments and electric current settings was attained. During each procedure, the expert explained the basic steps, from initial mucosal incision to complete dissection of the submucosa. Prior to ESD, lesions were discussed using various classifications such as Paris classification, laterally spreading tumor (LST) type, Kudo, NICE and JNET. This made choice of lesion and ESD therapeutic strategy more transparent to the 


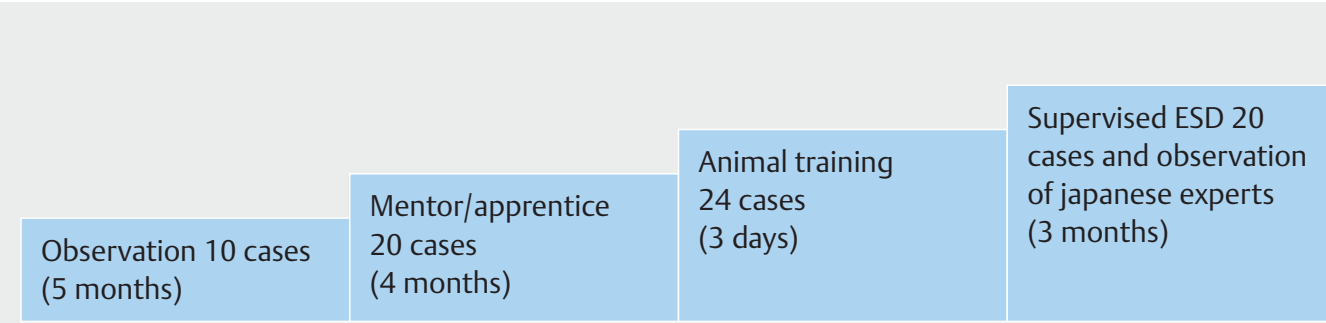

Training period

Fig. 2 Step-up training for ESD.
Independent ESD

phase

(12 months)
Study period, subdivided $1^{\text {st }}$ period: Month 1-6 $2^{\text {nd }}$ period: Month 7-12 trainee. The first step of observation, accumulation of basic ESD knowledge and preparatory training took about 5 months.

\section{Step 2: Mentor-apprentice phase}

This stage included the first hands-on phase of the training strategy whereby the trainee was allowed to perform simple tasks under close supervision. The tasks included, for example, injection and mucosal incision or submucosal dissection in a clear and easily recognizable cutting plane. Care was taken to choose lesions and situations feasible for the mentor-apprentice phase judiciously. Also, supervision remained close and the trainee was allowed only a short stretch of time to handle the knife. In the traditional mentor-apprentice stage in Japan, the mentor and the trainee exchange positions at fixed time intervals of about 5 to 15 minutes. The mentor-trainee stage blended well into the observation stage since the trainee actually spent a greater part of the time observing the mentor. The trainee had the opportunity to going through 20 ESD procedures in a mentor-apprentice fashion within a period of about 4 months.

\section{Step 3: Animal training workshop}

After the trainee had acquired basic knowledge of ESD, the next step was hands-on training of complete ESD procedures on an animal model. Three participants per team took turns of about 20 minutes each performing a total of 24 ESD on live piglets under the supervision of experts from Europe and Japan [9].

\section{Step 4: Clinical ESD under expert supervision}

After the ESD workshop on an animal model, the trainee was allowed to carry out human ESD cases, again in a step-up manner. In this phase, about 20 ESD cases were done under close supervision by an expert but without aiming for self-completion of the ESD. Again, lesions were chosen judiciously and difficult cases were ruled out. Simple cases in the rectum or distal stomach were attempted from the beginning by the trainee but the trainers were readily available for questions during each procedure in this phase, no case was done completely by the trainee alone. The most common problems encountered included control of hemorrhage, unclear dissection plane as well as uncertainty regarding the correct dissection strategy. Again, the principles of observation and mentor-apprentice tutoring were present. In Step 4, the trainee was able to work actively on the lesion over a longer period of time than in Step 2, because of the greater level of experience he had gathered during the animal model workshop.

\section{Step 5: Observation of Japanese experts in Germany}

The trainee subsequently visited an ESD observation course and could observe a Japanese expert performing about 8 ESD procedures within 2 days.

The training steps described are summarized in $\mathbf{\bullet}$ Fig. $\mathbf{2}$.

\section{Step 6: Independent ESD}

After completion of the steps described above, the trainee was then allowed to perform ESD cases independently. The lesions resected during this period were assessed together with the trainers prior to ESD. Thirty ESD procedures were performed in 12 months. This was defined as the study period as opposed to the training phase, which was termed the training period. The size of the resected specimen in $\mathrm{cm}^{2}$, LST type, location, en bloc and $\mathrm{R} 0$ resection rates, complication rates as well as resection speed were recorded prospectively.

\section{Study measures and definitions}

The aim of the study was to evaluate the feasibility and efficacy of a step-up approach for ESD training in a high-volume center in Germany. The primary study aim was to determine the level of competency attained after a step-up training program. ESD competency was defined as an en bloc resection rate $\geq 80 \%$ and a complication rate $\leq 10 \%$.

Complications were defined as major complications requiring further intervention such as re-endoscopy due to major post-interventional bleeding or surgery due to perforation.

The trainee's resection speed was recorded in $\mathrm{cm}^{2} / \mathrm{h}$. With the assumption that ESD specimens usually have an elliptical 


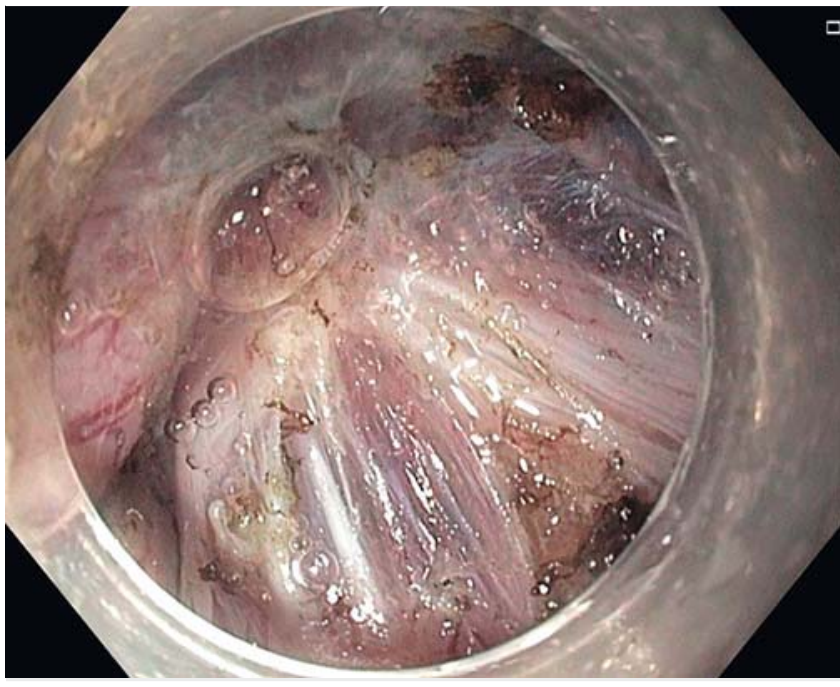

- Fig. 3 Muscle retracting sign.

shape, the area size of each specimen was determined using the formula (long diameter $/ 2 \times$ short diameter $/ 2 \times \pi$ ) $\mathrm{cm}^{2}$. This calculation was based on measurements of the specimen after it had been stretched and pinned onto the cork plate.

- Table 1 Overview of resected lesions in both study periods of about 6 months each. Size is shown as the median in both study periods.

\begin{tabular}{|c|c|c|c|}
\hline & $\begin{array}{l}\text { 1st study } \\
\text { period }\end{array}$ & $\begin{array}{l}\text { 2nd study } \\
\text { period }\end{array}$ & Total \\
\hline \multicolumn{4}{|l|}{ Location } \\
\hline - Stomach & 3 & 2 & 5 \\
\hline - Transverse colon & 0 & 1 & 1 \\
\hline - Descending colon & 0 & 1 & 1 \\
\hline - Sigmoid colon & 1 & 0 & 1 \\
\hline - Rectum & 11 & 11 & 22 \\
\hline \multicolumn{4}{|l|}{ Paris type } \\
\hline - Is & 0 & 0 & 0 \\
\hline - Ila & 12 & 14 & 26 \\
\hline - IIa+Is & 2 & 1 & 3 \\
\hline - IIa+IIc & 1 & 0 & 1 \\
\hline \multicolumn{4}{|l|}{ Histology } \\
\hline - LGIEN & 1 & 2 & 3 \\
\hline - HGIEN & 10 & 8 & 18 \\
\hline - Early carcinoma & 4 & 5 & 9 \\
\hline \multicolumn{4}{|l|}{ Size $\left[\mathrm{cm}^{2}\right]$} \\
\hline - All locations & 7.1 & 9.4 & 8.3 \\
\hline - Stomach & 4.5 & 5.7 & 5.1 \\
\hline - Colon/rectum & 9.7 & 9.4 & 9.4 \\
\hline
\end{tabular}

Histopathological definition of curative resection (R0) in the colorectum included tumor free lateral and vertical margins, without lymphatic or vascular involvement as well as an sm-invasion depth $<1000 \mu \mathrm{m}$ and no poorly differentiated histology [10]. Early stomach cancer had a differentiated histology and was limited to the mucosa (T1a) [11].

Finally, a learning curve was determined by dividing the procedures into two study periods. The first 15 ESD procedures were included in the first study period (about 6 months), while the second 15 ESD were in the second study period (also about 6 months). Competency criteria, en bloc resection rate, complication rate and speed in both study periods were compared. A follow-up examination for recurrence was done routinely after 3 months.

The study was discussed with and approved by the Institutional Review Board of Klinikum Augsburg Germany (BKF-35). All patients gave written informed consent prior to the intervention. They were informed personally by the study coordinator/trainee (A.E.). The study was conducted in accordance with the ethical principles of the Declaration of Helsinki and in compliance with good clinical practice and local regulations.

\section{Study population}

The study population comprised 30 patients with colorectal (n $=25)$ or gastric $(n=5)$ lesions referred to our institution for ESD. Median age of the study population was 67 years (22 male patients and 8 female patients). Exclusion criteria were age $\leq 18$ years, patients with esophageal lesions and patients with lesions not eligible for ESD due to suspected deep submucosal invasion.

\section{Statistical analysis}

The two study periods were compared by an unpaired onetailed non-parametric Mann-Whitney U-test. Data were expressed as median \pm standard error of the median. Statistical significance was assumed at a $P$ value $<0.05$.

\section{Results}

Thirty ESD procedures were performed independently in a 12month period after training Steps 1 to 5 . One ESD procedure in the rectum had to be abandoned due to suspected deep submucosal/muscular invasion seen as the so-called muscle-retraction sign ( $\triangleright$ Fig.3) and another ESD, also in the rectum, was switched to endoscopic piecemeal resection (EPMR) due to technical difficulties encountered because of the size and morphology of the lesion. The self-completion rate of the remaining 28 cases was $100 \%$.

During the 12-month phase of independent ESD, 4 lesions were resected in the antrum ( $4 \times$ Paris type Ila), 1 lesion in the upper stomach body (Paris type Ila), 22 in the rectum ( $2 \times$ Paris type Ila/Is, $1 \times$ Paris type Ila/Ilc, $19 \times$ Paris type Ila), 1 lesion in the sigmoid colon (Paris type Ila/Is), 1 lesion in the descending colon (Paris type Ila) and 1 lesion in the transverse colon (Paris type Ila) ( Table 1). Median specimen size was $8.26 \mathrm{~cm}^{2}$.

Twenty-eight of 30 lesions (93\%) were resected en bloc. All macroscopic en bloc resections were curative R0 in the histopathologic assessment (93\%). Median resection time for all le- 
- Table 2 Results of the study shown for both study periods of about 6 months each subdivided according to the location of the lesion. Resection time and resection speed are shown by the median in both study periods.

\begin{tabular}{|c|c|c|c|}
\hline & 1st study period & 2nd study period & Total \\
\hline All locations & 15 & 15 & 30 \\
\hline - Curative resection (R0) & $13(87 \%)$ & $15(100 \%)$ & $28(93 \%)$ \\
\hline - Complications & $1(7 \%)$ & $1(7 \%)$ & $2(7 \%)$ \\
\hline - Resection time [min] & 115 & 85 & 93 \\
\hline - Resection speed $[\mathrm{cm} 2 / \mathrm{h}]$ & 4.4 & 7.1 & 6.8 \\
\hline Stomach & 3 & 2 & 5 \\
\hline - Curative resection (R0) & $3(100 \%)$ & $2(100 \%)$ & $5(100 \%)$ \\
\hline - Complications & 0 & 0 & 0 \\
\hline - Resection time [min] & 90 & 63 & 75 \\
\hline - Resection speed $[\mathrm{cm} 2 / \mathrm{h}]$ & 3.6 & 5.6 & 4.4 \\
\hline Colon/rectum & 10 & 13 & 23 \\
\hline - Curative resection (R0) & $8(80 \%)$ & $13(100 \%)$ & $21(91 \%)$ \\
\hline - Complications & $1(10 \%)$ & $1(8 \%)$ & $2(6 \%)$ \\
\hline - Resection time [min] & 140 & 85 & 100 \\
\hline - Resection speed [cm2/h] & 4.8 & 9.2 & 7.1 \\
\hline
\end{tabular}

sions was 92.5 minutes while median resection speed was $6,77 \mathrm{~cm}^{2} / \mathrm{h}$ ( $\triangleright$ Table 2 , $\triangleright$ Fig. 4).

One patient experienced major delayed bleeding requiring emergency endoscopic treatment 2 days after ESD in the rectum. One patient developed signs of peritonitis 3 days after ESD in the descending colon and underwent hemicolectomy due to delayed perforation ( $\downarrow$ Table 3 ).

Histology of the resected specimens showed 3 lesions with low grade intraepithelial neoplasia (LGIEN), 18 lesions with high-grade intraepithelial neoplasia and 9 lesions with early cancer. All the stomach lesions $(5 \times)$ were cancerous with welldifferentiated histology limited to the mucosa (T1a), 3 rectal lesions and 1 lesion in the transverse colon had low-risk T1-carcinoma as defined above ( $\triangleright$ Table $\mathbf{1}$ ).

\section{ESD competence and the learning curve}

To describe the learning curve as well as development of competency achieved through the step-up training strategy, ESD procedures performed in the first 12 months were divided in two equal study periods. Both study periods were comparable in terms of lesion type, histology and size ( $>$ Table 1, $>$ Fig. 2). In the first study period, 13 of 15 ESD were completed independently by the trainee while in the second study period, 15 out of 15 procedures were completed. The $\mathrm{R} 0$ resection rate in period 1 was $86,7 \%$ and in period 2, $100 \%$ ( $\triangleright$ Table 2, $\triangleright$ Fig. 2). The complication rate in both periods was 6,7\% (1/15) ( $\triangleright$ Table 3, - Fig.2). Although lesion size increased from $7.1 \mathrm{~cm}^{2}$ to $9.42 \mathrm{~cm}^{2}$, resection time dropped significantly from $115 \mathrm{~min}$ utes in period 1 to 85 minutes in period 2 ( $\mathbf{F i g . 4}$ ). Resection speed also showed a marked improvement from $4.35 \mathrm{~cm}^{2} / \mathrm{h}$ to
$7.07 \mathrm{~cm}^{2} / \mathrm{h}$ but failed to achieve a significant value due to the small sample size.

Resected lesions were then subdivided into two further categories: stomach lesions and colorectal lesions ( $\downarrow$ Table 2 ). Comparison of the study periods within these subgroups was also done using the criteria described above. For the colorectal lesions, specimen size was equal in both study periods $\left(9.7 \mathrm{~cm}^{2}\right.$ vs $9.4 \mathrm{~cm}^{2}$ ), however, a significant improvement in resection time from 140 minutes to 85 minutes was observed. Resection speed improved considerably from $4.8 \mathrm{~cm}^{2} / \mathrm{h}$ to $9.2 \mathrm{~cm}^{2} / \mathrm{h}$ but without achieving a significant value ( $\triangleright$ Table 2 , $\triangleright$ Fig. 4 ). For the subgroup of stomach lesions, the specimen size was comparable in both study periods $\left(4.5 \mathrm{~cm}^{2}\right.$ vs $\left.5.7 \mathrm{~cm}^{2}\right)$, resection time and resection speed improved insignificantly from 90 minutes to 62.5 minutes and $3.6 \mathrm{~cm}^{2} / \mathrm{h}$ to $5.6 \mathrm{~cm}^{2} / \mathrm{h}$, respectively ( $>$ Table 2, $>$ Fig. 4).

\section{Follow-up}

Twenty-eight patients who underwent complete ESD were followed-up endoscopically about 3 months later. Also, routine biopsy of the scar was done. None of these patients had a recurrent lesion. One patient who was switched to EMR was also followed up 3 months later, and EMR had to be repeated due to incomplete initial resection.

\section{Discussion}

In this paper, we present results of a step-up training program on a single endoscopist in a German high-volume center. The optimal way to train endoscopists in the method of ESD re- 

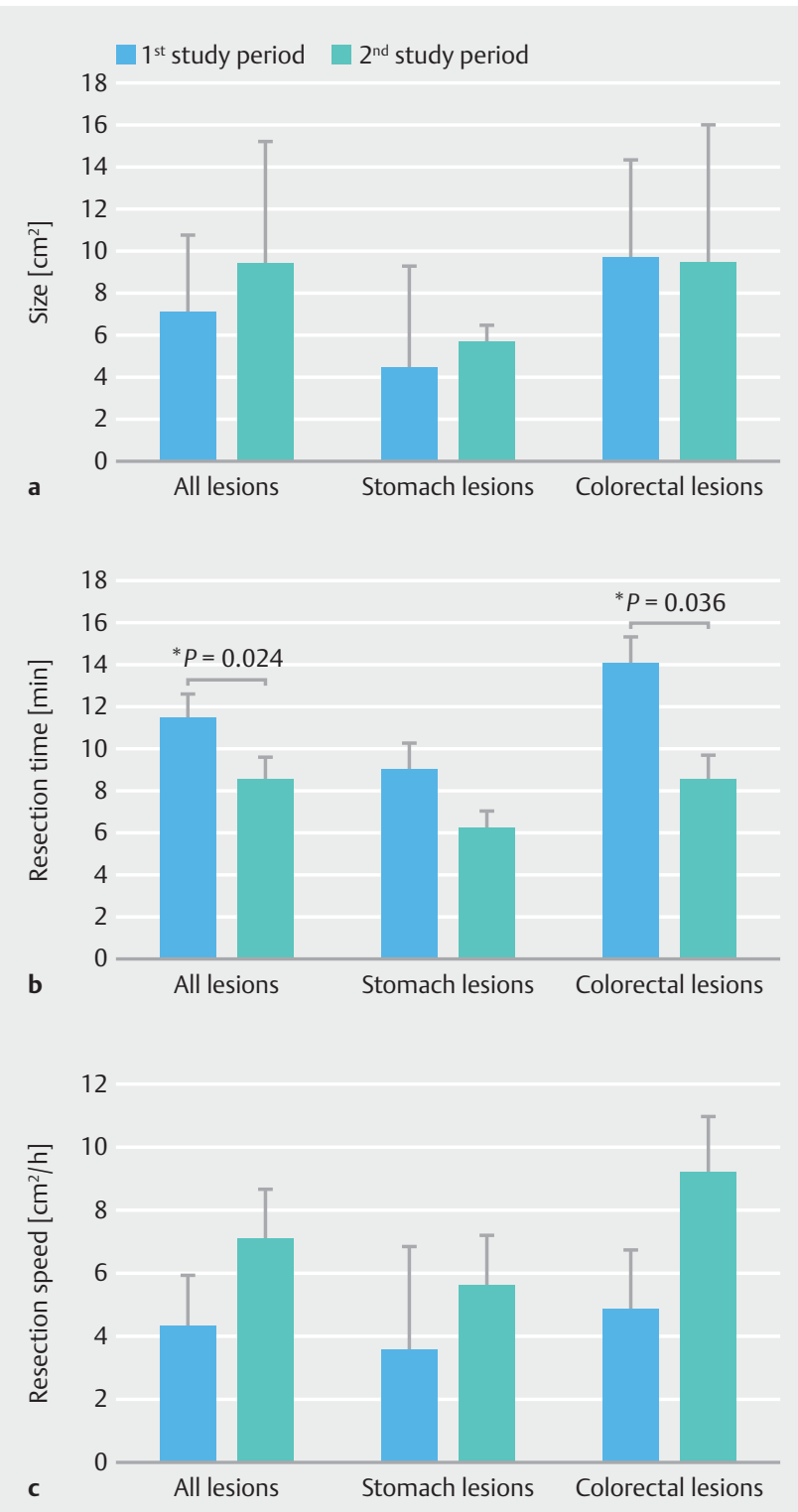

- Fig.4 Comparison of median size, median resection time and median resection speed between both study periods. Data represent median \pm standard error of the median. Significant $P$ values for the first versus second study period are included. mains an important issue and a point of debate. Sufficient data on ESD training strategies in Europe are lacking. In most Western countries, it is usually not possible for endoscopists to improve their skill by accumulating experience from easy stomach lesions. Using a step-up approach on mostly rectal lesions, a reasonably fast accumulation of skill was demonstrated in our study. The novel aspect of the data provided here is that after a short but intensive training phase on 50 clinical ESD cases and 24 animal cases over a period of about 12 months, the trainee was able to perform ESD in the rectum and stomach with excellent results, showing that the learning curve for acquiring basic ESD competency may be less steep in Europe than has been initially reported, at least for certain lesions in the rectum and lower stomach. This may make ESD training more accessible for qualified endoscopists in high-volume centers. However, a point of concern remains for colonic ESD especially in the proximal colon. In this study, even though two proximal colonic ESD cases were successfully performed after the training phase, a perforation rate of $50 \%$ (1/2 cases) was observed. ESD in the proximal colon remains a challenge, and due to the anatomical difficulties associated with such lesions, the proximal colon may not be an optimal location for training ESD beginners. Choice of lesions for the first 30 independent ESD procedures was deliberately limited almost completely to the rectum and lower stomach. Due to the low availability of stomach lesions eligible for beginner ESD in Europe, it is necessary to include rectum lesions for ESD training. Because the rectal wall is thicker than the colonic wall, risk of perforation is lower. Furthermore, the rectum is less prone to peristaltic motion, lesions are easier to access with fewer folds and a straighter view. Controlling the scope is often less difficult than in the colon or upper stomach, and bleeding is probably easier to control than in the upper stomach or esophagus. Finally, the consequence of perforation of the rectal wall is less dire than in the colon or esophagus. However, rectal lesions involving the anal canal may not be optimal for beginner ESD because of difficult scope control as well as higher risk of bleeding.

Training on an animal model was necessary to widen the scope of practical ESD skill. Although the animal model stomach is far from the reality of the human stomach, this stage is necessary to acquire basic skills. The possibility of conducting a large number of complete animal procedures under expert supervision in a short period of time rapidly increases the level of confidence. The advantage of training on live piglets as opposed to ex vivo models is the fact that bleeding complications can be practiced more efficiently. Also, respiratory movements

- Table 3 Overview of complications within the 12-month study period (independent ESD phase).

\begin{tabular}{|l|l|l|l|}
\hline & 1st study period & 2nd study period \\
\hline Major complications & & & \\
\hline - Perforation requiring surgery & 0 & 1 & 1 \\
\hline - Delayed bleeding requiring endoscopic intervention & 1 & 0 & 1 \\
\hline - Complication rate & $1(7 \%)$ & $1(7 \%)$ & $2(7 \%)$ \\
\hline
\end{tabular}


in a pig mimic the real-life setting better. The pig stomach has many similarities to the human stomach but with a lower degree of fibrosis.

The mentor-apprentice approach described above can be situated either before or after the animal model training stage. Although a greater part of this phase is spent observing the mentor, the trainee nonetheless can gather first hands-on experience under close supervision of the mentor. Before independent ESD cases are performed, a certain number of cases must be carried out under expert clinical supervision using the principles of observation and those of the mentor-apprentice approach.

In the mentor-apprentice stage and in the stage of supervised ESD cases, the trainee always had the knowledge and experience of the experts at his disposal. This makes a significant difference, especially when the early era of ESD training in Europe comes to mind. Today's experts gathered their experience initially from a "do-it-yourself" approach with fewer opportunities to witness experts and without the necessary feedback required for a faster learning curve. The mentor-apprentice steps in this study were probably the most useful for the trainee and, the immediate and first-hand feedback received from the trainers was perhaps the reason for the rapid increase in skill and competency within a short period of time. Furthermore, the excellent results produced after the training phase were also a product of pre-interventional discussions on strategy between the trainee and the trainer.

Also, observation included witnessing ESD procedures being done by Japanese experts. Draganov et al were able to show that the observation of live cases being done by Japanese experts can significantly improve the acquisition of ESD skills of western endoscopists [12].

Limitations of this study include the single-center, singletrainee design. It would have been desirable to compare the data with performance data from other trainees going through the same program. However, the results can be compared to data from other studies. In the study by lacopini et al [6], a short ESD training time led to an initial resection speed of about $45 \mathrm{~min} / \mathrm{cm}^{2}\left(1-2 \mathrm{~cm}^{2} / \mathrm{h}\right)$ in the rectum, which improved to about $12 \mathrm{~min} / \mathrm{cm}^{2}\left(5 \mathrm{~cm}^{2} / \mathrm{h}\right)$ after about 20 procedures. An overall en bloc resection and perforation rate in the rectum of $77 \%$ and $3 \%$, respectively was reported. Probst et al, without undergoing formal training, showed a resection speed of $16.6 \mathrm{~min} / \mathrm{cm}^{2}\left(3.6 \mathrm{~cm}^{2} / \mathrm{h}\right)$ after about 40 procedures, and an en bloc resection rate of $86 \%$ over a time frame of about 3 years. The lesions included here, however, were a mixed cohort from the stomach, rectum and esophagus [13].

A further limitation of this study is the bias produced due to the pretherapeutic discussion and choice of lesions together with the trainers, which may have led to treatment of easier and more favorable lesions in the study period.

\section{Conclusion}

A step-up training approach for ESD can lead to a high level of competency with a low complication rate within a short period of time, at least for easier locations in the rectum and lower stomach. ESD training should basically involve endoscopists from high-volume centers with sufficient experience in EMR. Furthermore, it seems feasible for candidates to begin their training in the rectum and avoid more complex locations such as the proximal colon.

\section{Competing interests}

None

\section{References}

[1] Probst A, Golger D, Anthuber M et al. Endoscopic submucosal dissection in large sessile lesions of the rectosigmoid: learning curve in a European center. Endoscopy 2012; 44: 660-667

[2] Oyama T, Yahagi N, Ponchon T et al. How to establish endoscopic submucosal dissection in Western countries. World J Gastroenterol 2015; 21: 11209-11220

[3] Fuccio L, Hassan C, Ponchon T et al. Clinical outcomes after endoscopic submucosal dissection for colorectal neoplasia: a systematic review and meta-analysis. Gastrointest Endosc 2017; 86: 74- 86

[4] Probst A, Ebigbo A, Märkl B et al. Endoscopic submucosal dissection for early rectal neoplasia: experience from a European center. Endoscopy 2017; 49: 222-232

[5] Coman RM, Gotoda T, Draganov PV. Training in endoscopic submucosal dissection. World J Gastrointest Endosc 2013; 5: 369-378

[6] lacopini F, Bella A, Costamagna G et al. Stepwise training in rectal and colonic endoscopic submucosal dissection with differentiated learning curves. Gastrointest Endosc 2012; 76: 1188 -1196

[7] Coda S, Trentino P, Antonellis F et al. A Western single-center experience with endoscopic submucosal dissection for early gastrointestinal cancers. Gastric cancer 2010; 13: 258-263

[8] Deprez PH, Bergman JJ, Meisner S et al. Current practice with endoscopic submucosal dissection in Europe: position statement from a panel of experts. Endoscopy 2010; 42: 853-858

[9] Berr F, Ponchon T, Neureiter D et al. Experimental ESD training in a porcine model: learning experience of skilled western endoscopists. Dig Endosc 2011; 23: 281-289

[10] Tanaka S, Kashida H, Saito Y et al. JGES guidelines for colorectal endoscopic submucosal dissection/endoscopic mucosal resection. Dig. Endosc 2015; 27: 417-434

[11] Bosman FT, Carneiro F, Hruban RH et al. WHO classification of tumours of the digestive system. World Health Organization classification of tumours. Tumors of the stomach. Lyon, France. I: ARC; 2010: $45-80$

[12] Draganov PV, Chang M, Coman RM et al. Role of observation of live cases done by Japanese experts in the acquisition of ESD skills by a western endoscopist. World J Gastroenterol 2014; 20: 4675-4680

[13] Probst A, Golger D, Arnholdt $\mathrm{H}$ et al. Endoscopic submucosal dissection of early cancers, flat adenomas, and submucosal tumors in the gastrointestinal tract. Clin Gastroenterol Hepatol 2009; 7: 149-155 